\title{
Descentralização do Estado, controle e participação social na educação no Brasil, Argentina e Colômbia
}

\author{
Decentralization of the State, control and social participation \\ in education in Brazil, Argentina and Colombia.
}

\section{La décentralisation de L'état et la relation avec le contrôle et la participation social à l'éducation au Brésil, en Argentine et en Colombie}

\author{
Diego Dartagnan da Silva Tormes ${ }^{1}$ \\ Rosane Carneio Sarturi ${ }^{2}$ \\ Marilene Gabriel Dalla Corte ${ }^{3}$
}

RESUMO: Analisou-se aproximações e distanciamentos no processo de descentralização do Estado na Argentina, Brasil e Colômbia concentrando-se na existência de dispositivos legais de controle e participação social nesses sistemas educacionais. A análise usa conceitos de educação comparada de Bray e Kai (2010) e Ferreira (2008), de Centeno (2015), Casassus (1990) e Di Gropello (1999) sobre descentralização na América Latina. Encontrou-se diferentes níveis de descentralização e diversos elementos de controle e participação social. No Brasil e Colômbia a descentralização chegou à gestão das escolas e projeto pedagógico. Na Argentina o processo foi menos profundo, ocorrendo de forma mais acelerada nos anos 90 , mas também chegando às escolas.

Palavras-chave: Descentralização, Controle Social, Participação Social, Sistemas Educacionais, Educação Comparada.

ABSTRACT: Approximations and distances were analyzed in the process of decentralization of the State in Argentina, Brazil and Colombia, concentrating on the existence of legal devices of control and social participation in these educational systems. The analysis uses concepts of comparative education from Bray and Kai (2010) and Ferreira (2008), from Centeno (2015), Casassus (1990) and Di Gropello (1999) on decentralization in Latin America. Different levels of decentralization and various elements of control and social participation were found. In Brazil and Colombia, decentralization has reached the management of schools and pedagogical projects. In Argentina the process was less profound, occurring in a more accelerated way in the 90's, but also arriving at schools.

Keywords: Decentralization. Social Control, Social Participation, Educational Systems, Comparative Education.

\footnotetext{
${ }^{1}$ Universidade Federal de Santa Maria. E-mail: diegotormes2@gmail.com

${ }^{2}$ Universidade Federal de Santa Maria. E-mail: rcsarturi@gmail.com

3 Universidade Federal de Santa Maria. E-mail: marilenedallacorte@gmail.com
} 
RÉSUMÉ: Dans cette étude nous avons comparé les différences et similarités dans les phénomènes politiques de décentralisation de l'État qui ont existé en Argentine, Brésil et en Colombie. Nous avons eu comme intérêt d'étude les différents dispositifs légaux qui ont été mise en place dans les trois pays à partir des années 90 et qui ont eu comme fonction contrôler la participation sociale des individus dans le choix d'organisation des systèmes éducatifs. Les auteurs comparatistes utilisés ont été Bray et Kai (2010) et Ferreira (2008) et pour discuter la décentralisation en Amérique Latine nous avons choisi Centeno (2015), Casassus (1990) et Di Gropello (1999). L'analyse réalisée nous a amené à conclure que dans les trois pays il y a eu distincts niveaux de décentralisation et dispositifs de contrôle et participation sociale. Au Brésil et Colombie le phénomène de la décentralisation a influencé directement la manière de fonctionnement des écoles et de leurs projets d'établissements. En Argentine les conséquences ont été moins visibles au départ mais les politiques de décentralisation menées après les années 90 ont rattrapé le Brésil et la Colombie notamment dans la forme de l'organisation de l'école publique.

Mots-clés: Décentralisation, Contrôle Social, Participation Sociale, Systèmes Éducatifs, Éducation Comparée. 
A década de 90 foi um período de revisão e modernização do Estado na América Latina $(A L)$ e de desenvolvimento de mecanismos constitucionais ou infraconstitucionais, que dessem suporte a essas mudanças. Algumas reformas do Estado foram sugeridas por organismos internacionais ocorrendo em toda a região e os impactos desse processo tendem a ser muito diferentes em cada país variando devido às questões locais, como o tamanho do país, com a organização do Estado, se federado ou unitário e, sem dúvida, impactando na educação no sentido de descentralizá-la, partir da reorganização do Estado.

O presente artigo surge no intuito de refletir acerca desse processo, tratando-se de um estudo que objetiva: analisar aproximações e distanciamentos entre três sistemas educativos nacionais com base em revisão bibliográfica e análise de documentos legais a respeito dos processos de descentralização do Estado ocorrido na Argentina, Brasil e Colômbia a partir dos anos noventa. Especial enfoque deu-se acerca da existência ou não, a partir da descentralização do estado nesses países, de dispositivos constitucionais ou infraconstitucionais que mencionassem modelos ou atores de controle e participação social ou estatal nos seus sistemas educacionais.
Cabe mencionar que, em virtude da extensão do presente texto bem como da variedade e diversidade de organização dos Estados Nacionais na AL, optou-se em estabelecer um recorte e analisar somente esses países em função de terem uma organização do Estado Federado ou próximo da forma federada ${ }^{4}$ e tratarem-se de grandes populações latino-americanas, como também possuírem significativo número de matrículas na educação obrigatória se comparada aos demais países da região.

Tal artigo surge a partir das reflexões realizadas no âmbito do Programa de Pósgraduação em Educação da Universidade Federal de Santa Maria (UFSM) e articulase com as leituras e pesquisas realizadas no âmbito do Programa Observatório da Educação (OBEDUC), fomentado pela Coordenação de Aperfeiçoamento de Pessoal de Nível Superior (CAPES), desenvolvido pelo Grupo de Pesquisa Elos/CNPq (UFSM). Optou-se por iniciar uma descrição breve do contexto educacional de cada país, para depois explicitar as bases conceituais e elementos de análise e, na sequência, a análise propriamente dita.

\footnotetext{
${ }^{4}$ A Colômbia, constitucionalmente é um Estado unitário e descentralizado. Ou seja, não é uma federação por definição, mas organiza-se de forma descentralizada. Essa descentralização, tem aproximações práticas com a
}

lógica de uma federação, pois há dispositivos legais de distribuem o poder e repartem competências, pelo menos em matéria educacional. 


\section{Fundamentação teórica}

Os países em questão estão entre os maiores territórios do continente e, no caso do Brasil entre os mais populosos. Brasil é o maior país em extensão territorial e em número de habitantes da $A L$, a Argentina é - segundo maior país em extensão territorial, já a Colômbia, em que pese o menor em território, tem a terceira maior população do continente. Quando analisamos os indicadores educacionais dos países percebemos que a distância quantitativa é imensa em relação aos demais países da região ou mesmo entre si.

Quadro 1 - Dados populacionais e de matrícula dos países analisados.

\begin{tabular}{|l|c|c|c|}
\hline \multicolumn{1}{|c|}{ DADOS } & ARGENTINA & BRASIL & COLOMBIA \\
\hline População & 44,27 milhões & 209,3 milhões & 48,74 milhões \\
\hline Matrículas na educação obrigatória & 14,04 milhões & 47,78 milhões & 11,20 milhões \\
\hline
\end{tabular}

Fonte: Indicadores Estadísticos del Sistema Educativo del Mercosur (MERCOSUR, 2012), FEDESARROLLO Centro de Investigación Económica y Social

Dentro desse universo populacional e de população em idade escolar tão diverso um do doutro foi possível perceber que as mudanças propostas para a AL durante os anos 90, teve alguns impactos também nesses sistemas educacionais, apesar das diferenças estruturais e quantitativas. O sistema educacional argentino mudou desenvolvendo a ideia de quatro níveis educacionais: inicial, primário, secundário e superior. A etapa inicial vai até os 5 anos sendo esse último obrigatório, a secundária começa aos 6 anos e vai até aos 12 anos de idade, já a secundaria atende jovens dos 12 aos 17 anos e, depois disso a educação superior que não é obrigatória e se ocupa dos cursos de graduação e pós-graduação. No Brasil, onde também ocorreram mudanças na educação básica obrigatória no mesmo período, há duas etapas (educação básica e superior) sendo que essas são subdividas. A educação básica compreende 3 etapas: educação infantil $(0$ até 5 anos), ensino fundamental (6 até os 14 anos) e ensino médio (15 até os 17 anos) sendo que a matrícula é obrigatória dos 4 aos 17 anos. A educação superior é dividia em duas etapas, graduação e pósgraduação, que não são de matrícula obrigatória. O sistema educacional colombiano é formado por quatro níveis: a) o pré-escolar que compreende, no mínimo, um ano obrigatório aos 5 anos de idade; b) a educação básica que dura nove anos e está dividida em dois ciclos: a educação básica primária de cinco anos e a educação básica secundária de quatro anos, c) a educação média com duração de dois anos; e, d) educação superior, essa não obrigatória.

O presente trabalho trata-se de um estudo que busca as aproximações $e$ distanciamentos com base em revisão bibliográfica e análise de documentos legais em relação aos processos de descentralização do Estado ocorrido nesses países, analisando a existência ou não, a partir desse processo, de dispositivos legais que mencionem 
modelos ou atores de controle e participação social ou estatal nos sistemas educativos dos países selecionados.

Para isso buscou-se as ideias de Bray e Kai (2010), quando tratam da comparação entre sistemas de ensino, mencionando que esse tipo de comparação possui larga tradição no campo da educação comparada (EC) e se encontra nas origens desse campo de estudo. Contudo, valendo-se das ideias desses autores não se deve esquecer que analisar sistemas educativos nacionais não significa necessariamente analisar os sistemas existentes dentro do sistema nacional. Ideia essa muito relevante no presente estudo uma vez que os países em questão são Estados Federados que contam com grande autonomia dos sistemas subnacionais, em especial a partir da descentralização do Estado ocorrida na década de 90. Nesse estudo, assim como Bray e Kai (2010), entende-se sistema nacional de educação como o conjunto de ações ou estruturas nacionais vinculadas ao poder estatal que, em geral, possui ações de ensinar, ofertar, regular e controlar a educação local.

O uso da metodologia de estudo comparado nesse trabalho foi uma escolha no sentido de, como diz Ferreira (2008), desenvolver uma dinâmica de raciocínio para identificar semelhanças e diferenças entre os sistemas de ensino analisados e interpretá-los considerando o contexto histórico e social no qual se encontram. Ferreira (2008) ainda menciona diferentes abordagens nos estudos em educação comparada entre elas aponta a abordagem que denomina de sócio-dinâmica, a qual traduz da seguinte forma:
Estamos seguramente sobre uma perspectiva que recusa ser só portadora da denúncia ou da constatação. Ela pretende ser pró-activa, construir saber, contribuir para um conhecimento mais consciente e para políticas e práticas mais conscienciosas no domínio da educação. Ela deve integrar a ingenuidade necessária, que já outras abordagens demonstraram, para que a Educação Comparada seja portadora de um saber com sentido que incorpore a esperança de um mundo melhor (Ferreira, 2008, p. 137).

Longe de ser tão amplo e pretencioso, mas com a necessidade de descrever, entender e construir saberes acerca dos modelos ou atores de controle e participação social ou estatal existentes nos sistemas educacionais estudados, é assim que se pretende escrever tal trabalho. Países distintos, com colonização diferentes e com diferença de mais de um século na organização de seus sistemas educacionais apresentam semelhanças nas mudanças educacionais ocorridas na transição do século $X X$ para o século $X X I$.

Os sistemas educacionais analisados passaram, como já foi dito, por mudanças na década de 90 dentro do processo de descentralização do Estado, ocorrido de modo geral na AL. Centento (2015), Casassus (1990) e Di Gropello (1999) abordam amplamente a questão da descentralização e da democratização da educação na América Latina. Di Gropello (1999) ao analisar modelos de descentralização educativa na $A L$, menciona que se considera descentralização a transferência de responsabilidades do governo central para autoridades públicas autônomas ou 
semiautônomas ou ainda para entes subnacionais. Nesse caminho de transferência de responsabilidades a autora menciona que esse processo pode significar, em virtude da falta de capacidade técnica dos níveis subnacionais, baixa participação da comunidade na tomada de decisões a respeito da gestão dos serviços descentralizados, nesse caso, a educação. A autora faz um amplo estudo sobre os graus de autonomia delegadas aos entes subnacionais estabelecendo categorias de graus de descentralização, entre eles, um modelo de descentralização chamado principal agente de intensidade média no qual " [...] los niveles subnacionales tienen un grado de independência relativamente elevado em casi todas las principales funciones, pero siguen respondendo em medida importante al nível central [...]" (Di Gropello, 1999, p.157).

Sobre essa categoria de descentralização um dos limites é o fato de que a dependência do financiamento central e do controle do poder central tornam difícil o equilíbrio entre autonomia e controle no processo de descentralização das relações entre os atores locais e centrais. Esse processo de descentralizar serviços educacionais, segundo a autora, ocorreu na maioria dos países da região seja por questões econômicas fiscais, por reorganização do papel do Estado, por questões de eficiência ou de ampliação da participação social.

Ao analisar a descentralização dos sistemas educativos na AL, Casassus (1990) menciona que a disposição do nível central em desfazer-se voluntariamente de poderes que historicamente Ihe pertenciam, situa-se no nível político estratégico de legitimação do Estado. Nesse sentido é possível pensar que, além de demandas de organismos internacionais ou de uma agenda neoliberal no continente, o processo de descentralização pode localizar-se na perspectiva de manter o poder e a legitimação do papel central dos Estados Nacionais em períodos de contestação desse poder. Essa situação, segundo o autor, está mais situada no âmbito da crise do papel do Estado central na região e a necessidade maior fortalecimento e aproximação com a sociedade civil. Ou seja, esse processo de descentralização educacional deve ser entendido como "[...] una respuesta a las insuficiencias para resolver los diversos problemas educacionales que em distinto grado han demonstrado poseer los Estados centralizados de la región [...]" (Casassus,1990, s.p.). Afirmar essa ideia não significa desconsiderar a relação do processo de descentralização educativa ocorrido na região com o endividamento dos países da região junto ao Fundo Monetário Internacional (FMI). Há que se pensar que esse processo teve efeitos democratizantes, não somente no acesso ao sistema educativo, como também na participação social nos processos de gestão educativa na região. Variadas foram as manifestações concretas desse processo e, na sequência, nos propomos a analisar os dados coletados de alguns aspectos, quais sejam, a existência ou não de dispositivos que mencionem modelos ou atores de controle e participação social ou estatal nos seus sistemas educacionais. 
Como principal elemento de coleta de dados usou-se os textos legais, constitucionais ou normativos, existentes nos países analisados, localizados em sites institucionais de cada país. Além disso, dados estatísticos sobre a quantidade matrículas e população em idade escolar de cada um dos sistemas educacionais analisados foram coletados em sites oficiais dos países ou em sites internacionais como do Mercado Comum do Sul (MERCOSUL).

Esses dados foram analisados de forma qualitativa quando analisados os números coletados em relação ao tamanho do sistema educacional de cada país e, o elemento principal, de forma qualitativa no caso do texto jurídico coletado para análise. Ainda sobre o processo de coleta e análise de dados cabe mencionar que se trata de um estudo multicasos considerando que se analisou três sistemas nacionais distintos, torna-se mais relevante a definição de estudo de multicasos que, segundo Barros e Lehfeld (2014, p. 84) é um modelo de estudo voltado para a análise e estudo de mais de um caso em particular. Ao tratar dos estudos de caso, Creswell (2010, p. 38), afirma que "[...] os estudos de caso são estratégias nas quais 0 pesquisador explora profundamente um programa, um evento, uma atividade, um processo ou um ou mais indivíduos". Definição essa que parece muito pertinente já que nos detemos num estudo por longo período que iniciou com a comparação entre Brasil e Argentina e, agora, amplia-se com a análise do caso colombiano.

\section{Apresentação e discussão}

A respeito do processo de descentralização do Estado brasileiro em relação aos serviços educacionais, vale ressaltar que desde a década de 1930 os sistemas estaduais de educação já estavam funcionando e, em escala menor, os sistemas municipais. Mas foi a partir da década dos anos 1970, no período ditatorial, que a municipalização se desenvolve com força e, na década de 1980, chamada década da redemocratização, a nova Constituição Federal de 1988 (CF/88), reorganizou o papel e as funções do Estado elevando os municípios à condição de ente federado e Ihes dando autonomia para instituírem seus sistemas de ensino com prioridade de oferta para a educação infantil ( 0 até os 5 anos) e, de forma compartilhada com os estados, o ensino fundamental ( 6 aos 14 anos). Além disso, a nova CF/88 trouxe como princípio constitucional na gestão da educação "gestão democrática, na forma da lei." (Brasil, 1988). Na prática esse princípio significou o surgimento de mecanismos de participação nos municípios e nas escolas como forma concreta de descentralização do Estado. 
A partir de 1996 a Lei de Diretrizes e Bases da Educação (LDB) (Brasil,1996), surgem os conselhos estaduais e municipais de educação, órgãos normativos dos respectivos sistemas de ensino como reflexo da existência anterior do Conselho Nacional de Educação (CNE). Tais conselhos são regidos por leis próprias aprovadas no âmbito dos estados e municípios e, de acordo com o estabelecido na LDB/96:

Art. 14. Os sistemas de ensino definirão as normas da gestão democrática do ensino público na educação básica, de acordo com as suas peculiaridades e conforme os seguintes princípios:

I - participação dos profissionais da educação na elaboração do projeto pedagógico da escola;

II - participação das comunidades escolar e local em conselhos escolares ou equivalentes.

Art. 15. Os sistemas de ensino assegurarão às unidades escolares públicas de educação básica que os integram progressivos graus de autonomia pedagógica e administrativa e de gestão financeira, observadas as normas gerais de direito financeiro público. (Brasil, 1996).

Percebe-se que a CF/88 influenciou outros marcos regulatórios, nesse caso a LDB/96, que aprofundou a descentralização dos serviços educacionais do nível central para os níveis subnacionais até chegar nas escolas. A CF/88 e a LDB/96, não somente descentralizaram a responsabilidade pela oferta e pela matrícula, como também dotaram de autonomia de gestão os entes subnacionais. A determinação é que os sistemas de ensino definam normas de gestão democrática considerando a participação dos professores e da comunidade escolar. Menciona ainda o projeto pedagógico da escola, numa clara referência de autonomia da escola brasileira na construção de seu próprio projeto e, ainda, a existência de conselhos escolares formados pela comunidade. Esses procedimentos demonstram a intenção do Estado central em não somente demandar a responsabilidade pela oferta do serviço educacional para os demais entes federados, como também demandar a existência de participação da comunidade escolar e dos professores na gestão da educação. Importante mencionar ainda o Art.15 da LDB/96 sobre a responsabilidade dada aos sistemas de ensino subnacionais para que aumentem a autonomia administrativa, pedagógica e financeira das escolas. Esses elementos são interessantes, pois, não somente os entes federados são atores no processo de descentralização do Estado tendo suas competências ampliadas, mas as escolas também passaram a ter mais autonomia e responsabilidades.

Em relação aos conselhos, é importante dizer que, no Brasil, as competências dos conselhos escolares são muito variadas, uma vez que eles são regulamentados pelas leis de cada município, mas de modo geral, pode-se dizer que compete a eles, formados pelas comunidades escolares, participar nas decisões de gestão pedagógica e financeira das escolas. No que diz respeito aos conselhos de educação, a variedade de legislação se repete uma vez que cabe a cada município aprovar leis próprias sobre o tema, confirmado a tradição federada e a 
descentralização do país. Mas, de modo geral, esses conselhos são formados por pessoas das comunidades locais, podendo ser alunos, pais ou outros sujeitos, não necessariamente professores e gestores, com a função de fiscalizar e normatizar a oferta dos serviços educacionais no território de cada ente federado.

O processo de descentralização da educação argentina também foi grande, começando na década de 1970 com a transferência das responsabilidades da gestão dos estabelecimentos de ensino primários e secundários para as províncias. A "Constitución de la Nación Argentina" (Argentina,1994) (CNA) deixa claro a opção federada do país e, de acordo com a última alteração, em seu Art. $5^{\circ}$ dá plena autonomia para cada província construir sua própria constituição que considere também a autonomia do município. Assim, o federalismo argentino possui três entes federados (Nación, Ciudad Autónoma de Buenos Aires CABA - e as Províncias) e a existência de autonomia dos municípios depende de cada constituição provincial. O Art. 123, numa clara tendência à descentralização, reconhece a necessidade de as constituições provinciais assegurarem autonomia dos municípios regulando o alcance da ordem institucional, administrativa e financeira dos municípios. $\mathrm{Na}$ prática, a descentralização até os níveis municipais, no caso argentino, é muito variada e pouco fortalecida.

A Ley de Educación Nacional 26.206 (Argentina, 2006), logo nos artigos iniciais, traz vários elementos que ampliam e fortalecem o processo dedescentralização educacional quando menciona a responsabilidade dos entes federados, sem mencionar responsabilidades dos municípios, confirmando a tendência da descentralização até as províncias. O Art. 11 dessa lei determina os fins e objetivos da educação argentina, entre eles: "Asegurar la participación democrática de docentes, familias y estudiantes en las instituciones educativas de todos los niveles" (Argentina, 2006). Aqui é importante perceber que a lei menciona a participação democrática nas instituições educativas, algo que pode assemelhar-se ao princípio constitucional brasileiro de gestão democrática. Ampliando essa noção, o Art. 67 dessa lei, ao mencionar os direitos e deveres dos docentes, elenca entre eles: "A la activa participación en la elaboración e implementación del proyecto institucional de la escuela" (Argentina, 2006). A partir dessas mudanças legais pode-se perceber que a descentralização, não somente entregou responsabilidades para as províncias, mas também chegou até a porta da escola dotando-a de responsabilidades específicas.

Outro elemento existente na "Ley Federal de Educación" é o "Consejo Federal de Educación" que é formado por membros da comunidade acadêmica, do Congresso Nacional, organizações de trabalho e organizações de docentes. Isso é importante uma vez que esse conselho participa do processo de avaliação da educação nacional, coordena a política educacional e propõe critérios e modalidades para o desenvolvimento do sistema educacional argentino. Assim, ter elementos como grêmios docentes 
inseridos nesse processo pode ser um mecanismo de democratização e participação na gestão e avaliação da educação nesse país.

Outro elemento a ser mencionado no caso argentino é a "Ley de Cooperadoras Escolares, Ley 26.759" sancionada em 2012. Essa lei coloca a escola e a comunidade escolar em evidência ao determinar que:

El Estado nacional, las provincias y la Ciudad Autónoma de Buenos Aires garantizan -conforme la Ley de Educación Nacional 26.206- la participación de las familias y de la comunidad educativa en las instituciones escolares en general y, en particular, a través de las cooperadoras escolares, como ámbito de participación de las familias en el proyecto educativo institucional, a fin de colaborar en el proceso educativo de los alumnos y alumnas (Argentina, 2012).

Percebe-se que garantir a participação através das "cooperadoras"(é uma responsabilidade não somente uma possibilidade), dentro do Estado descentralizado possibilita maior participação e controle social na gestão da escola. Entre as responsabilidades das cooperados estão: "[...] democratización de la gestión educativa; mejora de los establecimientos escolares, fomento de prácticas solidarias y de cooperación." (Argentina, 2012). Pode-se pensar que tal ação descentraliza ainda mais as responsabilidades do Estado Nacional, levando a responsabilidade, também para as escolas e para as comunidades escolares no sentido de melhorar a qualidade educacional. Os demais artigos dessa lei mencionam a necessidade de regulamentação em cada província ou município sobre o funcionamento das cooperadoras incluindo as possibilidades de captação de recursos para as escolas.

A descentralização educacional na Colômbia, também ocorreu como forma de modernização do Estado e de equilíbrio e distribuição de responsabilidades entre os entes, sem perder de vista o poder central do Estado Nacional. De forma geral, boa parte dos pesquisadores na área mencionam que esse processo começa nos anos 80 através do Decreto-Ley 077 de 1987 pelo qual se expediu o Estatuto de la Descentralización en benefício de los municípios (Colombia, 1987). Nessa época, segundo Prieto:

En la totalidad de los municipios se planteó como dificultad para la aceptación de la Ley la falta de claridad en cuanto a la disponibilidad de los recursos financieros y económicos para asumirla, situación que llevó a creer que la descentralización había sido promovida más para traspasar los problemas del nivel central al local que para el manejo eficaz, efectivo y eficiente de la educación. (Prieto, s/a, s/p)

Realidade essa que se percebe, pelo menos incialmente, também no Brasil e na Argentina, uma vez que, descentralizadas as funções do ponto de vista legal, a realidade mostrou que os problemas de financiamento das demandas educacionais passaram também a estar descentralizados, ou seja, a cargo dos entes subnacionais. Mas foi na década de 90 , com a nova constituição aprovada em 1991, que o processo iniciado anteriormente toma força jurídica e prática. Logo no Art. $1^{\circ}$ da nova constituição há o conceito de que "Colombia es un Estado 
social de derecho, organizado en forma de República unitaria, descentralizada, con autonomía de sus entidades territoriales, democrática, participativa [...]" (Colombia, 1991) e o resultado desse processo significou, na prática, a organização do Estado distribuído nas seguintes esferas administravas: departamentos, distritos, municípios e territórios indígenas. Não se deve esquecer que o Estado é unitário, mas descentralizado, ou seja, cada ente subnacional tem autoridades próprias, estrutura administrativa e elementos legais que determinam funções e objetivos fazendo com que grande parte da administração do Estado central seja descentralizada às demais esferas de governo subnacionais. Seguindo a orientação constitucional, em 1992 se reorganizou o Ministério de la Educación Nacional (MEN) através do Decreto 2127 (Colombia. 1992) pelo qual as funções do ministério seriam de orientação do setor educativo, formulação das políticas atuando como assessoria para o serviço educacional, de forma complementar às ações municipais e de intermediação entre a Nação e os municípios. Ou seja, cabe ao Estado central somente a ação complementar ao papel desenvolvido pelos municípios na oferta de serviços educacionais. Em 1993 com a Lei № 60, ocorre a definição das competências da nação, dos distritos, dos departamentos e dos municípios para a administração da saúde e educação.

No ano de 1994, com a descentralização do serviço educacional do centro para os departamentos e municípios, através da Ley 115, Ley General de Educación (LGE) ocorre a descentralização pedagógica e curricular. Essa lei propôs alguns elementos de controle e participação social ou estatal nos sistemas educacionais, como mencionado no Art. 6ㅇ a "comunidade educativa" que consiste na presença de pais, alunos, professores, egressos do sistema escolar, entidades profissionais que podem participar da direção dos estabelecimentos de ensino. Essa participação, segundo a lei, consiste em "[...] participarán en el diseño, ejecución y evaluación del Proyecto Educativo Institucional y en la buena marcha del respectivo establecimiento educativo." (Colombia, 1994). Essas funções podem aproximar a comunidade da gestão da escola, trazendo elementos de fora do poder estatal para a gestão escolar. Aqui faz-se uma ressalva que essa participação ocorre, pelo que diz a lei, no âmbito da gestão escolar e não na gestão do sistema educacional como um todo.

Em artigos posteriores a LGE apresenta vários elementos de controle e participação social ou estatal nos seus sistemas educacionais departamentais e municipais bem como no nacional. Um exemplo é o Art. 142. Determinando que: "Cada establecimiento educativo del Estado tendrá un gobierno escolar conformado por el rector, el Consejo Directivo y el Consejo Académico." (Colombia, 1994). Aqui há dois elementos distintos que fazem parte da gestão da escola um é conselho diretivo que tem funções como aprovar o plano anual de atualização de pessoal, participar no planejamento e avaliação do "Proyecto 
Educativo Institucional', estimular e controlar o bom funcionamento da institucional; participar na avaliação anual dos docentes, entre outras. O outro é o conselho académico que atua com funções de estudar e modificar o currículo, pensar o plano de estudos; promover a avaliação institucional anual. Os dois conselhos, formados por elementos da comunidade, ainda que distintos, atuam na gestão da escola e nas questões pertinentes ao currículo e avaliação de alunos e professores e não na gestão do sistema educacional nacional, departamental ou municipal.

Do ponto de vista nacional os elementos que atuam na gestão da educação são o MEN e o Congresso Nacional da República, sendo que o primeiro tem funções de planejamento, inspeção, vigilância, administração e normativo da educação nacional. Já os departamentos e municípios, segundo previsão dos Artigos 151 a 153, tem as seguintes funções: a) departamentos: velar pela qualidade $\mathrm{e}$ cobertura da educação em seu respectivo território; estabelecer as políticas, planos e programas departamentais e distritais de educação, de acordo com os critérios estabelecidos pelo MEN; organizar o serviço educativo estatal de acordo com as prescrições legais e supervisionar o serviço educativo prestado por entidades oficiais e particulares; b) municípios: administrar a educação nos municípios, organizar, executar, vigiar e avaliar os serviço educativo; nomear, remover e transferir e dar licenças aos docentes, e pessoal administrativo; orientar, assessorar e dirigir a educação no município; todo de acordo com o estabelecido na LGE. Em linhas gerais o que se pode ver é que os departamentos e municípios também possuem funções específicas de gestão do sistema educacional no âmbito de sua competência e território.

Há ainda um elemento muito interessante para o presente estudo que aparece no âmbito da nação, dos departamentos e dos municípios que são "las juntas y foros" previstos nos artigos 155 a 167. Existe a "Junta Nacional de Educación" (JUNE), as "Juntas Departamentales y Distritales de Educación" e a "Junta Municipal de Educación" (JUME), cada uma dessas juntas, no âmbito de sua competência é formada por integrantes do Estado como $o$ alcalde municipal, o secretário municipal, o ministro de Estado, o secretário departamental de educação, congressistas e membros da sociedade como dois representantes dos educadores designados pela organização sindical, representante das comunidades indígenas ou campesinas, representante do setor produtivo, etc. As funções dessas juntas são de verificar se as políticas, objetivos, metas e planos elaborados pelo MEN e pela JUNE, cumprem-se nos departamentos; verificar se os currículos das instituições educativas atendem aos critérios estabelecidos em lei, verificar se as políticas, objetivos, planos e programas educativos nacionais se cumprem nos municípios; fomentar, avaliar e controlar o serviço educacional no seu município etc. Especificamente no que diz repito às juntas o que se percebe é que as mesmas, pelo menos no que diz a lei, são um elemento 
de participação da sociedade na gestão do sistema educacional como um todo em cada ente subnacional. Essa gestão propõe-se a ocorrer com a participação de atores estatais e sociais.

Já os foros estão também previstos na lei, mas tem outra característica:

ARTICULO 164. Objeto y organización periódica. Créanse los Foros Educativos municipales, distritales, departamentales y nacional con el fin de reflexionar sobre el estado de la educación y hacer recomendaciones a las autoridades educativas respectivas para el mejoramiento y cobertura de la educación. Serán organizados anualmente por las respectivas autoridades y reunirán a las comunidades educativas de su jurisdicción. (Colombia,1994)
Considerando a principal função desse fórum que é refletir sobre o sistema educacional, participam dele, além de autoridades do Estado, membros de universidades, institutos de pesquisa social e econômica, a igreja, representante dos professores universitários, representante das centrais de trabalhadores, representante de associações econômicas, representantes das famílias, representantes dos grupos étnicos etc. Ou seja, mais um ator de participação na gestão, mas dessa vez com funções distintas, funções mais voltadas para a análise e estudos sobre a realidade educacional e sugerindo alterações e mudanças no planejamento e execução da educação municipal, distrital, departamental e nacional.

\section{Considerações}

Analisando os processos de descentralização do Estado ocorrido nos países estudados, com foco na existência ou não, de dispositivos constitucionais ou infraconstitucionais que mencionem modelos ou atores de controle e participação social ou estatal nos seus sistemas educacionais, percebeu-se mais aproximações que distanciamentos entre os três sistemas educativos em questão.

Em que pese o fato de Brasil e Argentina definirem-se como federações e Colômbia definir-se como Estado unitário descentralizado que, na prática aproximase da lógica federativa, o processo de descentralização do Estado aconteceu nos três países e com impactos profundos na organização do sistema educacional chegando até mesmo às escolas. Esse processo no Brasil é mais antigo e, talvez em função disso, estar mais amplo e profundo, já na Argentina e na Colômbia também ocorreram processos de descentralização que, não somente descentralizaram 0 Estado Nacional colocando a responsabilidade da oferta e gestão da educação na mão dos entes subnacionais, como também possibilitou maior democratização das relações na gestão educacional. Centeno (2015) fez amplo estudo a respeito do processo de democratização e inclusão educacional na $\mathrm{AL}$ mostrando que no período em que a descentralização do Estado se desenvolveu ampliou-se também o acesso ao sistema educacional. 
No caso brasileiro a autonomia dos municípios é um traço forte da descentralização do Estado, determinada pela $\mathrm{CF} / 88$ e pela $\mathrm{LDB} / 96$, que significou, na prática, o surgimento de Conselhos Municipais de Educação (CME) e de sistemas municipais autônomos de educação, além da autonomia da escola através de conselhos escolares. Ou seja, a descentralização, no Brasil, não somente deu autonomia aos municípios, mas inseriu, no texto jurídico, novos atores como os CME e os conselhos escolares com a intenção de ampliar a participação social e a democratização da gestão educacional no âmbito dos municípios e das escolas.

Já na Argentina o processo de descentralização, a julgar pelos documentos analisados, foi menos radical chegando somente até as províncias. A autonomia dos municípios não existe de forma constitucional e depende das forças políticas e tradições ideológicas de cada província ao aprovar leis que deem poderes aos municípios. Na educação argentina percebe-se a descentralização para as províncias, mas a própria legislação determina que a responsabilidade é cooperada entre a Nação, CABA e as províncias. Há a existência de atores de controle e participação social como as "cooperadoras escolares" ou estatal no caso do "Consejo Federal de Educación".

Considerando que as "cooperadoras escolares" são formadas por membros da comunidade, considera-se esses atores como de controle e participação social, já o "Consejo Federal de Educación" pode ser considerado de controle estatal uma vez que o Congresso Nacional Argentino e o
Ministério da Educação desse país também fazem parte desse conselho, além de entidades sociais. Em geral, a descentralização do Estado, na Argentina, gerou dispositivos legais ou normativos que possibilitam a existência de atores e elementos de participação e controle social e estatal da educação, bem como pode ter fortalecido o acesso à educação e a democratização da gestão educacional nos dois casos estudados.

Colômbia, apesar de sua constituição não dizer que o Estado é federado, ao usar a definição constitucional de que a "Colombia es un Estado social de derecho, organizado en forma de República unitaria, descentralizada, con autonomía de sus entidades territoriales [...]" (Colombia,1991) passa agir como se fosse federado e, principalmente descentralizado. Essa descentralização começou antes da Constituição de 1991, mas foi a partir da LGE de 1994 que esse processo de descentralização se institucionalizou na educação colombiana. Parte desse processo de institucionalização foi a atribuição de responsabilidades aos departamentos, distritos e municípios não somente na oferta como também no financiamento. No que diz respeito ao foco desse estudo percebeu-se, pelas legislações estudadas, que na Colômbia também o processo de descentralização veio acompanhado de elementos legais de democratização da gestão como as JUNE, as JUME e os foros e os consejos. Espaços esse onde a sociedade civil e elementos do Estado debatem, propõe e fiscalização e refletem sobre o serviço educacional colombiano. Todos elementos distintos 
atuando cada um no âmbito de suas competências territoriais e administrativas.

Em linhas gerais, percebeu-se que 0 processo de descentralização do Estado vivido no continente a partir dos anos 90 significou, nos casos estudados, a descentralização da oferta e da gestão dos serviços educacionais do Estado Nacional para as esferas de governo subnacionais. Possibilitou ainda 0 surgimento de mecanismos legais que permitem espaços participação social na gestão do sistema educacional e das escolas o que pode ter levado a consequente ampliação da democratização da gestão. A descentralização, nos três casos estudados, tem um traço comum que foi o processo gradativo, ao longo dos anos noventa e início do século $X X I$, de descentralização de serviços a partir do surgimento de mecanismos legais, significando diferentes movimentos e profundidades. Ao descentralizar ainda mais seu sistema educacional o Brasil dotou de autonomia pedagógica, de gestão e financeira as escolas e os sistemas e trouxe a comunidade escolar para pensar a gestão e as políticas públicas no setor. $\mathrm{O}$ mesmo passou na Colômbia que, ao instituir distintos mecanismos de participação pode, em tese, ter ampliado a participação da sociedade no debate educacional. No caso argentino o processo se deu de forma mais lenta adentrando o século $\mathrm{XXI}$, mas também criando espaços de participação da comunidade, mas ainda com forte presença do Estado Nacional como ocorre no caso do Consejo Federal de Educación onde o poder Executivo e o Legislativo do país têm participação.

Outros estudos caberiam sobre a operacionalização desses espaços se, a partir da possibilidade legal de sua existência, os mesmos têm efetivamente funcionado e garantido a participação social na gestão da educação, quer no sistema educacional como um todo, quer na gestão das escolas. Os três países estudados possuem características federadas e há outros na região com essas ou outras características que poderiam ter vivido distintos processos políticos e sociais nos últimos trinta anos. Contudo, pode-se pensar, a julgar pelo tamanho e representação política dos sistemas estudados, uma tendência no continente, no sentido de que a descentralização, seja por diminuição dos encargos do Estado Nacional, seja por legitimação do poder central, seja por maior demanda de autonomia das esferas subnacionais, seja por determinação de organismos internacionais, provocou também a possibilidade de mecanismos e processos de democratização da gestão e participação social. 


\section{Referências}

Argentina (1994). Ley nํ24.430, de Diciembre 15 de 1994. Constitución de la Nación Argentina.

Argentina (2006). Ley oㅜ 26.206, de Diciembre 14 de 2006. Ley de Educación Nacional.

Argentina (2012). Ley no 26.759, de Agosto 8 de 2012. Ley de Coperadoras Escolares.

Barros, A. J. P. \& Lehfeld, N. A. S. (2014). Projeto de Pesquisa: propostas metodológicas.

Petrópolis: Rio de Janeiro.

Brasil (1988). Constituição da República Federativa do Brasil. De 5 de outubro de 1988.

Brasil (1996). Lei no 9394, de 20 de dezembro de 1996. Estabelece as Diretrizes e Bases da Educação Nacional.

Bray, M. \& Kai, J. (2010). La comparación de sistemas (C. P. Centeno, Trad.). In M. Bray, B. Adamson, \& M. Mason (Eds). Educación Comparada. Enfoques y métodos (pp. 159183). Buenos Aires: Granica.

Casassus, J. (1990). Descentralización y desconcentración de los sistemas educativos en América Latina: fundamentos y dimensiones críticas. In Proyecto Principal de Educación en América Latina y el Caribe: boletín, 22 (pp. 7-16). Recuperado de http://unesdoc.unesco.org/images/0008/000874/087493s.pdf.

Centeno, C. P. (2015). Avances y límites del proceso de democratización e inclusión educativa en América Latina en el siglo XXI (2015). V Congreso Internacional de Estudios Comparados en Educación, Buenos Aires. Recuperado de http://www.saece.org.ar/docs/congreso5/trab097.pdf.

Colombia (1987). Decreto 77 de Enero 15 de 1987. Por el cual se expide el estatuto de descentralización en beneficio de los municipios.

Colombia (1991). Constitución Política de Colombia. De Julio 6 de 1991.

Colombia (1992). Decreto 2127 de Diciembre 29 de 1992. Por el cual se reestructura el ministerio de educacion nacional.

Colombia (1993). Ley 60 de Agosto 12 de 1993. Por la cual se dictan normas orgánicas sobre la distribución de competencias de conformidad con los artículos 151 y 288 de la Constitución Política y se distribuyen recursos según los artículos 356 y 357 de la Constitución Política y se dictan otras disposiciones.

Colombia (1994). Ley 115 de Febrero 8 de 1994. Por la cual se expide la ley general de educación. Ministério de Educación Nacional.

Creswell, J. W. (2010). Projeto de Pesquisa: métodos qualitativo, quantitativo e misto. (3 ed.) Porto Alegre: ARTMED.

Di Gropello, E. (1999). Los modelos de descentralización educativa en América Latina.

Revista CEPAL, 68, 153-170. http://hdl.handle.net/11362/12183. 
Ferreira, A. G. (2008). O sentido da educação comparada: uma compreensão sobre a construção de uma identidade. Educação, 31(2), 124-138. Recuperado de http://revistaseletronicas.pucrs.br/ojs/index.php/faced/article/view/2764/2111.

MERCOSUR (2012). Indicadores Estadísticos del Sistema Educativo del Mercosur 2012. Recuperado de http://edu.mercosur.int/pt-BR/estatisticas/finish/1328-indicadoreseducacionaismercosur/822-indicadores-educacionais-mercosur-2012.html.

Prieto. P. C (s/d). La Descentralización educativa en Colombia: perspectivas y realidad. Recuperado de http://decon.edu.uy/network/M00/caballer.pdf.

Recebido em 10 de janeiro de 2019

Aprovado em 01 de novembro de 2019 